\title{
ADDED VALUE OF HUMAN BIOMONITORING IN ASSESSMENT OF GENERAL POPULATION EXPOSURE TO XENOBIOTICS
}

\author{
Katarína Kromerová1, 2 , Vladimír Bencko² \\ ${ }^{1}$ Public Health Authority of the Slovak Republic, Bratislava, Slovak Republic \\ ${ }^{2}$ Institute of Hygiene and Epidemiology, First Faculty of Medicine, Charles University and General University Hospital in Prague, Prague, Czech \\ Republic
}

\begin{abstract}
SUMMARY
Human biomonitoring (HBM) has a wide range of applications and long tradition both in health care and the field of public health. Its major advantage is the integration of all exposure routes and sources. Since HBM information is an integrated exposure finding it offers the opportunity to trace and mimic a realistic exposure scenario. It reduces the number of assumptions that need to be made when estimating exposure and thus helps to reduce the uncertainties in exposure science. In spite of some challenges, such as further harmonization in the area of HBM, necessity of deriving equivalents of markers of external exposure and addressing the ethical and political aspects of its application, HBM is an efficient and cost-effective way to measure exposure levels of the human body to xenobiotics.
\end{abstract}

Key words: xenobiotics, exposure, mercury, human biomonitoring

Address for correspondence: K. Kromerová, Public Health Authority of the Slovak Republic, Trnavská 52, 82645 Bratislava, Slovak Republic. E-mail: katarina.kromerova@uvzsr.sk

https://doi.org/10.21101/cejph.a5348

\section{INTRODUCTION}

People are exposed to thousands of chemicals in work and the environment via air, water, food and soil. More than 10,000 chemical contaminants can enter the human body by skin, ingestion and respiration. The general population experiences uncontrolled multi-chemical exposure from many different sources at doses around or well below regulatory limits. First ever exposure occurs in the uterus (1).

A plethora of chemicals from anthropogenic and natural origins enter animal feed, human food and water either as undesirable contaminants or as part of the components of a diet. Anthropogenic contaminants of public and animal health importance include persistent organic pollutants (i.e. dioxins, polychlorinated biphenyls (PCBs), brominated flame retardants, perfluoroalkyl acids), Maillard reaction products (acrylamide, furans), phthalates, pharmaceuticals, as well as residues from production aids and chemicals authorized for use following a pre-marketing approval in food and feed productions such as pesticides/biocides, and food and feed additives. Important classes of natural contaminants include heavy metals such as lead, cadmium, uranium, mercury, and metalloids such as arsenic and natural toxins produced by bacteria, protozoa, algae, fungi, and plants (2).

Risk is defined by the WHO International Programme on Chemical Safety (IPCS) as "the probability of an adverse effect in an organism, system, or (sub)population caused under specified circumstances by exposure to an agent" (3). Complete elimination of the risk is an unrealistic objective and the circumstances and level of exposure are important aspects (1). People in modern societies are exposed to a wide spectrum of environmental chemicals. Exposure to some of them may be associated with adverse health effects. Knowledge of population exposure to these substances is therefore crucial for estimation of associated health risks (4).

There have been significant advances in techniques for obtaining available data. Despite this development, however, exposure information for $95-99 \%$ of the 100,000 chemicals with potential toxicity is still unavailable (5).

Assessment of population exposure to environmental chemicals is based on two methodological approaches: environmental monitoring, i.e. analysis of pollutants in environmental media and calculation of human exposure according to their intake and measurement of environmental chemicals in human body fluids and tissues, i.e. human monitoring. For assessment of exposure and body burden a combination of both approaches can be recommended (4).

In 2002, the National Research Council of the United States of America defined human biomonitoring (HBM) as a method for assessing human exposure to chemicals by measuring chemicals or their metabolites in human tissues or specimens such as blood or urine (6). HBM relies on the use of biomarkers, measurable indicators of changes or events in biological systems. Biomarkers are measurements of the concentrations of chemical substances, their metabolites or reaction products in human tissues or specimens such as blood, urine, hair, adipose tissue, teeth, saliva, breast milk, and sperm (7). 


\section{Added Value and Advantages of Human Biomoni- toring}

It was shown that heterogeneity in biological measurements is less likely to skew results than heterogeneity in external exposure (8). Thus, HBM is a sound solution for addressing chemical 'events' leading to fewer uncertainties (9).

The main advantage of using biomarkers is intrinsic in their nature, representing an integrative measurement of exposure to a given agent (i.e. the internal dose) that results from complex pathways of human exposure and also incorporates toxicokinetic information and individual characteristics such as a genetically based susceptibility (10). It takes into account processes such as metabolism, bioaccumulation and excretion (7). Through the use of biomarkers it is not only possible to monitor exposure but it also becomes feasible to detect early health effects (10).

HBM can show geographical, age and socioeconomic differences in exposure and body burden (7). As an example, it is possible to demonstrate that the homeless population in Prague (including non-smoking homeless women) faces a greater risk of cadmium exposure than the majority of Prague's sheltered population. Older adults can also be more vulnerable to health effects from chemical exposure than young people (11). HBM programmes have shown that several metals appear to accumulate in the elderly population. Findings of the Flemish Environment and Health Survey (FLEHS) showed that the highest levels of total mercury in blood were found in the elderly (aged 50-65) (12). In a group of seniors, it was found that higher blood lead levels were significantly associated with chronic kidney disease and stroke, but the blood mercury level in this group was significantly lower compared to blood donors (4). Pregnant women and their newborns in particular are populations with high susceptibility risks because chemical exposure in pregnant women could result in prenatal exposure of newborns to chemicals via the placenta (7). The EU-wide DEMOCOPHES project showed elevated levels of methyl mercury in fish eating subgroups of the investigated populations (i.e. mothers) (7), and the Norwegian MoBa cohort study reported a negative association between maternal exposure to mercury (via reported dietary intake during pregnancy) and birth weight (13). The Japanese Tohoku HBM study also reported a negative relationship between maternal hair mercury levels and motor abilities of infants (14). DEMOCOPHES included school children and their mothers and was able to demonstrate age differences in body burdens (7). Furthermore, the study designs of many HBM programmes often include data collection of multiple factors from participants such as gender, living environment (urban vs. rural), lifestyle habits (e.g. smoking, vegetarians), medical history (e.g. diabetes) etc. These factors have been proven useful for determining additional risk factors of higher chemical body burden. HBM can help to link the following factors with chemical exposure:

- influence of gender on mercury load: boys had higher levels of mercury than girls (GerES IV study), men had higher levels of mercury than women (PROBE study) whereas in another study women had higher levels of mercury in blood and urine than men (CZ-HBM study);

- impact of a region on the body burden of mercury: the levels of mercury in blood and urine were higher among children in urban areas (Slovenia HBM study) (7);

- influence of genetic polymorphism on mercury load: interin- dividual variations in biomarker levels can have an important genetic component (15).

Another major advantage of HBM is the possibility of reducing the number of assumptions that have to be made regarding consumption rates. Thus, HBM helps to further reduce the uncertainties in exposure science (7).

Another advantage is integration over all routes and sources that may elucidate exposures that have not been anticipated or have been neglected in external aggregate exposure assessments and/or models. For complex health risk assessment of the general public HBM surveys are the ideal exposure data collecting tool (7). For example, the Human Early Life Exposome (HELIX) project measures the environmental exposure of up to 32,000 European mother-child pairs and its consequent impact on the growth, development and health of children. It estimates prenatal and postnatal exposure to a broad range of chemical and physical factors: persistent and non-persistent organic chemicals, metals, pesticides, environmental tobacco smoke, water contaminants, air pollutants, noise, UV radiation, and contact with green spaces. Part of the project comprises a collection of extensive biomarker data for a subset of 1,200 mother-child pairs (16).

However, biological measures of exposure are preferable, if available, to environmental exposure data as they are closer to the target organ dose and provide greater precision in risk estimates and in dose-response relationships. HBM is often more specific and sensitive than environmental monitoring (e.g. food monitoring) in assessing the degree of recent and indeed past exposure to chemicals from all routes (17). Internal doses, i.e. concentrations in fluids (urine, blood) or organs inside the body are relevant for reflecting actual exposure. Internal doses are also more relevant than external doses in providing a link between exposure and effects. They account for the dose to which target organs or systems are actually exposed to. In the context of human predictive toxicology there is an increase in the use of models coupling human toxicokinetics modelling and dose-response models relating internal dose and effects at target level, as shown, for instance, by Péry et al. (18) to predict acetaminophen hepatotoxicity in humans from effects measured in vitro on hepatic cell lines (19).

Long-term external monitoring data are always lacking, and external exposure cannot be determined to completely account for internal exposure (20). HBM can be used for revealing longterm trends for contaminants in the population and indicate likely environmental implications. For example, a remarkable 13-fold increase of perfluorooctane sulfonate (PFOS) has been observed in women in China (9).

Furthermore, HBM can help develop physiologically based pharmacokinetic models (PBPK models) that reflect the absorption, distribution, metabolism and excretion process (ADME process). Redding et al. used physiological parameters from a population cohort in Taiwan and reference values given in the literature to estimate partition coefficients based on chemical structure and lipid content in various body tissues (21). They also utilised exposure data from Japan to predict the acquired PCB-153 body burdens at an average child-bearing age of 25 years. Good agreement between HBM measurements and prediction indicated the feasibility of the application of biomonitoring data in human health risk assessment (9).

By reconstructing the allocation of relevant pathways with advanced statistical techniques HBM may offer solutions for expo- 
sure minimisation or even elimination (9). Modelling approaches from HBM data could be used for generating consistent input data for human exposure assessment. For example, Ulaszewska et al. (22) used HBM data of PCB levels in breast milk from Italian women and PBPK models to determine the most probable scenario of exposure: for each congener, the authors determined the most probable long-term history of PCB emission in air as well as concentrations in environmental receptor media and food, and estimated the time evolution of daily intakes over a lifetime. As a result, they were able to accurately reconstruct exposure and supplement the data gaps on environmental concentrations over a period of decades. Such reverse modelling that uses HBM data can generate data for human health risk assessment (19).

Since HBM information is an integrated exposure finding, it offers the opportunity to trace and mimic a realistic exposure scenario (23).

HBM has also contributed to research on the economic consequences of mercury exposure. Pacyna et al. have estimated that on a global scale lost economic productivity from mercury pollution could reach \$ 29.4 billion in 2020 (24). Studies have also highlighted the considerable economic benefits of environmental pollution prevention in the US and worldwide (25). The DEMOCOPHES results on mercury were used for an economic calculation of the cost of actual exposure of Europeans to this widespread heavy metal (26).

HBM and biomarkers have a long tradition in health care. They are used in curative and preventive medicine in several domains and may be applied in a different context to environmental health. In occupational medicine HBM has played an important role in measuring the body burden of toxic substances and their metabolites for over a century. HBM is also used in particular for detection of exposure and adverse health risk, assessing the efficiency of preventive measures and for controlling workplace limit values. For certain industries and professions testing is mandatory. In public health HBM is used in population screening to identify people at risk of developing a specific disease at an early stage. Tests are administered not only to individuals who have no apparent symptoms but also to population groups with potentially elevated risk. In environmental health HBM is used together with other methods such as environmental monitoring and modelling for research, surveillance and awareness raising. In research studies, biomarkers are used to improve knowledge of causal links between environmental factors and health, often addressing or including (early) effect biomarkers and genetic factors (biomarkers of susceptibility).

HBM also enables development and re-evaluation of national reference values and checking of possible exceedance of healthrelated limit values (4).

HBM can support monitoring/surveillance of the efficiency of political risk reduction measures, provide data for identification of needs and priority settings in policy and contribute to a decision basis for management measures such as the establishment of limit values (7). HBM results are important for policy decisions, regulation of exposure and health risk assessment. They can be used by regulatory authorities or the government to enforce legislation, to give relevant answers to requests by NGOs or to assess population health risk in case of unusual emergency situations, such as the 2002 flooding of a plant that previously produced chlorinated pesticides with subsequent risk of release of dioxins into the surrounding environment (27). HBM results also serve as a strong argument for compliance with international agreements in the field of environmental influences on health such as the Stockholm Convention of 2001 regulating exposure to persistent organic compounds (POPs) or the prepared Minamata Convention reducing mercury levels in the environment and population body burden. Long-term downward trends of POPs in human breast milk or urinary mercury in non-smokers document the gradual decline of body burden (28).

HBM has become a primary tool for exposure assessment in a wide variety of contexts including population monitoring at national level, individual exposure assessments in the context of epidemiological research on potential adverse health effects of chemical exposure due to improvements in analytical chemistry, including growing lab capacity and reductions in cost, coupled with the increasing focus on more subtle exposure levels that involve more complex exposure sources and routes of exposure (29).

\section{Challenges of Human Biomonitoring}

Ideally, both the biomarkers of effect and the biomarkers of exposure should be associated closely with overall individual exposure to provide an exact measure of the internal dose or individual health risk. They should be sensitive, specific, biologically relevant, feasible, practical, and inexpensive. Seldom does a biomarker meet all of these criteria - most biomarkers represent a compromise of these criteria (10).

As biomarker concentrations vary both within and between individuals, the variations in biomarker concentrations observed in a population biomonitoring study are not easy to interpret. In addition, the biological media selected for sampling affect biomarker concentrations independent of other factors. Finally, renal or hepatic diseases in particular have an impact on biomarker variation (29).

Benefits and limitations of different sample types, including blood, hair, urine, or breast milk have been described at length (30).

With low tissue levels in the $\mathrm{ng} / \mathrm{kg}$ body weight range the detection of biomarkers can be an analytical challenge that is additionally complicated by contamination and the potential instability of conjugates. With urine sampling the type of sampling (spot urine, $24 \mathrm{~h}$ urine or morning void) is an important factor as is the use of volume-based or creatinine-based urinary concentrations. Changes in protein/fat composition and enzyme activity impact on the reliability of human milk samples (7).

Internal concentrations, i.e. concentrations in fluids (urine, blood) or organs inside the body, are relevant for reflecting actual exposure (19).

HBM data does not differentiate exposure by source, and HBM alone cannot provide information about the source of exposure or how long a chemical has been in the body. For translation of HBM data into daily exposure estimates there is need of a detailed understanding of the potential analytical/methodological pitfalls and of the toxicokinetics of the individual chemical (7).

In addition, HBM raises important ethical and privacy issues due to the fact that it involves taking samples from humans, sometimes in an invasive manner (blood samples) (7). The donation of tissues or fluids by healthy volunteers implies sensitive ethical and privacy issues. To ensure the protection of the rights and dignity 
of study participants a complex legal and ethical framework exists in Europe. One of the most important international references to define and safeguard fundamental human rights in the field of biomedical research, in particular of those participating in research, is the Oviedo Convention and its Additional Protocol concerning Biomedical Research. The Additional Protocol emphasizes the necessity of obtaining informed consent and requires that a research project is submitted to an ethics committee for independent examination of its scientific merit and multidisciplinary review of its ethical acceptability. The Data Protection Directive 95/46/EC (now replaced by General Data Protection Regulation) regulates the processing of personal data within the EU. It places obligations on organizations using personal information and gives individuals certain rights. Samples and data obtained in an HBM study are considered sensitive personal data related to health. Processing of such data is in principle forbidden, unless certain conditions are met. The issue of ethics and data protection has also been addressed by the twin projects COPHES (COnsortium to Perform Human biomonitoring on a European Scale) and DEMOCOPHES (DEMOnstration of a study to COordinate and Perform Human biomonitoring on a European Scale) (31).

\section{CONCLUSION}

HBM is an efficient and cost-effective way to measure the level of exposure of the human body to xenobiotics. Its advantage is the integration of all exposure routes and sources. Since HBM information is an integrated exposure finding, it offers the opportunity to trace and mimic a realistic exposure scenario. It reduces the number of assumptions that need to be made when estimating exposure and thus helps to reduce the uncertainties in exposure science. Other advantages include the possibility of clarifying human metabolic and contaminant toxicity mechanisms, its usability in case of the majority of xenobiotics and the fact that it reflects the internal dose of contaminant at the given point in time. However, further harmonization in the area of human biomonitoring is necessary in the light of results of the COPHES and DEMOCOPHES twin projects in order to derive equivalents of markers of external exposure and to address the ethical and political aspects of its application. Nevertheless, the overall benefits of HBM as part of a comprehensive approach to risk assessment are unquestionable and constitute a step in the desired direction by minimising uncertainty and approaching real exposure values.

\section{Acknowledgement}

This article was supported by the Grant Agency of the Czech Republic GACR 17-00859S

\section{Conflict of Interests}

None declared

\section{REFERENCES}

1. Kromerová K, Bencko V. Current trends in the process of risk assessment of exposure to xenobiotics including dietary intake. Hygiena. 2017;62(2):54-61. (In Slovak).
2. Dorne JL, Fink-Gremmels J. Human and animal health risk assessments of chemicals in the food chain: comparative aspects and future perspectives. Toxicol Appl Pharmacol. 2013 Aug 1;270(3):187-95.

3. IPCS- International Programme on Chemical Safety. IPCS risk assessment terminology. Harmonization project document, no. 1 [Internet].Geneva: WHO; 2004 [cited 2017 Sep 26]. Available from: http://www.who.int/ ipcs/methods/harmonization/areas/ipcsterminologyparts1 and2.pdf?ua1/1/4.

4. C Černá M, Puklová V, Hanzlíková L, Sochorová L, Kubínová R. 25 years of HBM in the Czech Republic. Int J Hyg Environ Health. 2017;220(2 PT A):3-5.

5. Egeghy PP, Judson R, Gangwal S, Mosher S, Smith D, Vail J, et al. The exposure data landscape for manufactured chemicals. Sci Total Environ. 2012;414:159-66.

6. Centers for Disease Control and Prevention. Biomonitoring data definition of the United States Centers for Disease Control and Prevention [Internet]. 2005 [cited 2017 Sep 26]. Available from: http://www.cdc. gov/healthywater/statistics/bio/.

7. Choi J, Aaroe Morck T, Polcher A, Knudsen LE, Joas A. A review of the state of the art of human biomonitoring for chemical substances and its application to human exposure assessment for food safety. External scientific report [Internet]. 2015 [cited 2017 Sep 26]. Available from: http://onlinelibrary.wiley.com/doi/10.2903/sp.efsa.2015.EN-724/pdf.

8. Fowler BA. Computational toxicology: methods and applications for risk assessment. London: Elsevier; 2013.

9. Dong Z, Liu Y, Duan L, Bekele D, Naidu R. Uncertainties in human health risk assessment of environmental contaminants: a review and perspective. Environ Int. 2015;85:120-32.

10. National Research Centre for the Working Environment. HBM definition of the Danish National Institute of Occupational Health [Internet]. 2007 [cited 2017 Sep 26]. Available from: http://www.arbejdsmiljoforskning. $\mathrm{dk} /$. (In Danish.)

11. Hrnčířová D, Batáriová $\mathrm{A}$, Černá $\mathrm{M}$, Procházka $\mathrm{B}$, Dlouhý $\mathrm{P}$, Andě M. Exposure of Prague's homeless population to lead and cadmium, compared to Prague's general population. Int J Hyg Environ Health. 2008;211(5-6):580-6.

12. Croes K, De Coster S, De Galan S, Morrens B, Loots I, Van de Mieroop $\mathrm{E}$, et al. Health effects in the Flemish population in relation to low levels of mercury exposure: from organ to transcriptome level. Int J Hyg Environ Health. 2014;217(2-3):239-47.

13. Vejrup K, Brantsaeter AL, Knutsen HK, Magnus P, Alexander J, Kvalem HE, et al. Prenatal mercury exposure and infant birth weight in the Norwegian Mother and Child Cohort Study. Public Health Nutr. 2014;17(9):2071-80

14. Suzuki K, Nakai K, Sugawara T, Nakamura T, Ohba T, Shimada M, et al. Neurobehavioral effects of prenatal exposure to methylmercury and PCBs, and seafood intake: Neonatal behavioral assessment scale results of Tohoku study of child development. Environ Res. 2010;110(7):699704.

15. Parajuli RP, Goodrich JM, Chou HN, Gruninger SE, Dolinoy DC, Franzblau A, et al. Genetic polymorphisms are associated with hair, blood and urine mercury levels in the American Dental Association (ADA) study. Environ Res. 2016;149:247-58.

16. Vrijheid M, Slama R, Robinson O, Chatzi L, Coen M, van den Hazel $\mathrm{P}$, et al. The human early-life exposome (HELIX): project rationale and design. Environ Health Perspect. 2014;122(6):535-44.

17. Manno M, Viau C, Cocker J, Colosio C, Lowry L, Mutti A, et al. Biomonitoring for occupational health risk assessment (BOHRA). Toxicol Lett. 2010;192(1):3-16.

18. Péry ARR, Brochot C, Zeman FA, Mombelli E, Desmots S, Pavan M, et al. Prediction of dose-hepatotoxic response in humans based on toxicokinetic/toxicodynamic modelling with or without in vivo data: a case study with acetaminophen. Toxicol Lett. 2013;220(1):26-34.

19. Ciffroy P, Péry ARR, Roth N. Perspectives for integrating human and environmental exposure assessments. Sci Total Environ. 2016;568:51221.

20. Bernillon P, Bois FY. Statistical issues in toxicokinetic modeling: a Bayesian perspective. Environ Health Perspect. 2000 Oct;108 Suppl 5:883-93.

21. Redding LE, Sohn MD, McKone TE, Chen JW, Wang SL, Hsieh DPH, et al. Population physiologically based pharmacokinetic modelling for the human lactational transfer of PCB-153 with consideration of worldwide human biomonitoring results. Environ Health Perspect. 2008;116:162935.

22. Ulazewska MM, Ciffroy P, Tahraoui F, Zeman FA, Capri E, Brochot C. Interpreting PCB levels in breast milk using a physiologically based 
pharmacokinetic model to reconstruct the dynamic exposure of Italian women. J Expo Sci Environ Epidemiol. 2012;22(6):601-9.

23. Dong Z, Hu J. Development of lead source-specific exposure standards based on aggregate exposure assessment: Bayesian inversion from biomonitoring information to multi pathway exposure. Environ Sci Technol. 2011;46(2):1144-52.

24. Pacyna JM, Sundseth K, Pacyna EG, Munthe J, Åstrom S, Panasiuk D; Nordic Council of Ministers, Copenhagen. Socio-economic costs of continuing the status-quo of mercury pollution [Internet]. 2008 [cited 2015 Aug 20]. Available from: http://www.norden.org/ sv/publikationer/ publikationer/2008-580/at_download/publicationfile.

25. Trasande L, DiGangi J, Evers DC, Petrlik J, Buck DG, Šamánek J, et al. Economic implications of mercury exposure in the context of the global mercury treaty: Hair mercury levels and estimated lost economic productivity in selected developing countries. J Environ Manage. 2016;183:229-

26. Bellanger M, Pichery C, Aerts D, Berglund M, Castano A, Cejchanova $\mathrm{M}$, et al.; Demo/Cophes. Economic benefits of methylmercury exposure control in Europe: monetary value of neurotoxicity prevention. Environ Health. 2013 Jan 7;12:3. doi: 10.1186/1476-069X-12-3
27. Černá M, Spěváčková V, Batáriová A, Šmíd J, Čejchanová M, Očadlíková $\mathrm{D}$, et al. Human biomonitoring system in the Czech Republic. Int J Hyg Environ Health. 2007;210(3-4):495-9.

28. Mikeš O, Čupr P, Kohút L, Krsková A, Černá M. Fifteen years of monitoring of POPs in the breast milk, Czech Republic, 1994-2009: trends and factors. Environ Sci Pollut Res Int. 2012 Jul;19(6):1936-43.

29. Ayward LL, Hays SM, Smolders R, Koch HM, Cocker J, Jones K, et al. Sources of variability in biomarker concentrations. J Toxicol Environ Health B Crit Rev. 2014;17(1):45-61.

30. Pausternbach D, Galbraith D. Biomonitoring and biomarkers: exposure assessment will never be the same. Environ Health Perspect. 2006;114(8):1143-9.

31. Casteleyn L, Dumez B, Becker K, Kolossa-Gehring M, en Hond E, Schoeters $\mathrm{G}$, et al. A pilot study on the feasibility of European harmonized human biomonitoring: strategies towards a common approach, challenges and opportunities. Environ Res. 2015;141:3-14.

Received March 20, 2018

Accepted in revised form August 3, 2018 